\title{
Assessing Factors Affecting Teaching and Learning of Mathematics in Some Selected Senior High Schools in Kumasi Metropolis
}

\author{
${ }^{1}$ Peter Anayitime, ${ }^{2}$ Emmanuel Adobah, ${ }^{3}$ Ebenezer Frimpong Ofobi \\ ${ }^{1}$ College Tutor, ${ }^{2}$ College Tutor, ${ }^{3}$ College Tutor \\ ${ }^{1} \& 3$ Mathematics \& ICT Department; Wesley College of Education; Box 1927; Kumasi; A/R; Ghana \\ ${ }^{2}$ Mathematics \& ICT Department; St. Louis College of education, Box 3041; Kumasi; A/R; Ghana
}

\begin{abstract}
:
The study sought to assess factors affecting teaching and learning of mathematics in some selected senior high schools (SHS) in Kumasi Metropolis of the Ashanti Region of Ghana. A descriptive survey was the research design used for the study. In all, a total of 90 respondents; made up of 10 SHS mathematics teachers and 80 SHS elective mathematics students were selected from five (5) SHS in the Metropolis. A purposive sampling technique of the non-probability sampling procedure was used to select the respondents for the study. Data obtained were analysed using both quantitative and qualitative data analysis methods. It was revealed that lack of mathematics laboratories/practical rooms; lack/inadequate mathematics practical activities and the use of lecture method in teaching mathematics were the three (3) major factors affecting SHS students in the learning of mathematics in the selected schools. Again, it was observed that lack of TLMs; heavy workload on mathematics teachers and lack of mathematics laboratories/practical rooms were three (3) major factors affecting mathematics teachers in the teaching of mathematics. Finally, it was revealed that provision and use of appropriate TLMs in teaching mathematics; and engaging students in hands-on and minds-on oriented lessons were some of the strategies that could be used to improve SHS students' academic performance in mathematics. It was therefore, recommended that Government of Ghana and other stakeholders in SHS education should build mathematics laboratories/practical rooms in all SHS in the country and also equip them with requisite TLMs so that students can learn mathematics in more practical-oriented manner instead theoretical approach being used in senior high schools.
\end{abstract}

Keywords:- Assessing, factors, affecting, teaching, learning, mathematics, senior high schools.

\section{Introduction}

According to Stephen (2009), mathematics is the mother or queen of all sciences and that it is a science that deals with the logic of shape, quantity and arrangement of things or events. The study added that mathematics is all around us; and it is the building block for everything that we do. These human mathematical activities are demonstrated right from the childhood of an individual.

Attah (2009) posited that children possess a natural curiosity and interests in mathematics and come to school with an understanding of mathematical concepts and problems solving strategies that they have discovered through exploration of the world around them. Abubakar (1980) opined that mathematics is the foundation of all science and also very embodiment of precision and brevity. This implies that the importance of mathematics in the life of a student cannot be overemphasised.

In the light of its importance, mathematics is one of the important subjects that are to be learnt by all students from basic school to higher level of education in Ghana. Because of its relevance, core mathematics is made compulsory for all senior high schools (SHS) students and even up to first year in some universities and other tertiary institutions in the country.

However, studies conducted in Ghanaian SHS over the years by (Mitchell Group, 2009; Buabeng, Owusu \& Ntow, 2014; Appiahene, Opoku, Akweittey, Adoba \& Kwarteng, 2014) have posited that mathematics has 
been and continue to be a difficult subject for the SHS students resulting in declining academic performance and poor attitudes towards mathematics as a subject.

In a comparative study on Ghana's SHS students' achievements in Trends in International Mathematics and Science Study (TIMSS) in 2003, 2007 and 2011, Buabeng, et al. (2014) concluded that Ghana's performance in mathematics relative to other African countries gives some indications that Ghanaian SHS students are not achieving at the levels expected when compared to students at same grade levels in other parts of the world; and as such there is the need to assess underlying causes of SHS students' underperformance in mathematics.

Odhiambo (2005) contended that there is a growing demand from the government and the public for teacher accountability. Heck (2009) also opined that teachers should not escape a portion of blame when students perform poorly. This implies that teachers should be held responsible when it comes to students' poor academic performance. Kimani, Kara and Njagi (2013) revealed that while blaming teachers for the poor performance of students, it very imperative to assess the factors affecting teachers and students in the teaching and learning of mathematics as a school subject.

In a study, Appiahene et al. (2014) attributed the poor performance of SHS students to several factors that affect teachers in the teaching of mathematics. In a similar study, Udeh, Edeoga and Okpube (2017) also attributed students' poor performance to numerous factors affecting or influence students in the learning of mathematics in schools.

It is hoped that when these factors confronting teachers and students are brought to light, it would help improve teaching and learning of mathematics in Ghanaian SHS, thereby impacting positively on the academic performance of students in mathematics.

It is against this background that this study was carried out to assess factors affecting teaching and learning of mathematics in some selected SHS in the Kumasi Metropolis of the Ashanti Region of Ghana.

\section{Statement of the Problem}

Mathematics educators, parents and other stakeholders in mathematics education have been worried about the poor performance of SHS students in the SSSCE, WASSCE as well as TIMMS mathematics examinations results for quite some time now.

Through extensive interactions with the teachers and students in some selected SHS in the Kumasi Metropolis, it was observed that the performance of SHS students in mathematics over the years in both internal and external examinations was not encouraging compared to other school subjects.

For example, a careful analysis of the WAEC mathematics examination results and the WAEC Chief Examiner's Reports over a five year period (2014-2018) in one of the best selected SHS for this study, revealed that students' performance in mathematics continue to yield poor results year after year. The analyses of the declined students' results for a five year period are presented in Table 1 below:

Table 1: Students' Performance In Five Years Mathematics WASSCE Examinations

\begin{tabular}{|c|c|c|c|}
\hline Year & Total No. Registered & $\%$ of students with pass & $\%$ of students with fail \\
\hline 2014 & 1,078 & 34.50 & 65.50 \\
\hline 2015 & 939 & 36.91 & 63.09 \\
\hline 2016 & 844 & 34.52 & 65.42 \\
\hline 2017 & 939 & 35.55 & 64.45 \\
\hline 2018 & 1,045 & 39.92 & 60.08 \\
\hline
\end{tabular}

Source: (WASSCE Mathematics Results \& WAEC Chief Examiner's Report, (2014 - 2018)

Data in Table 1 above shows that students' performance in WASSCE mathematics examinations over the past five year period was very poor and these could be attributed to several factors that might impede or hinder the teaching and learning of mathematics in senior high schools.

Studies by (Ezike \& Obodo, 1991; Fasasi, 2009; Yemi \& Adeshina, 2013) have attributed this poor performance in mathematics to factors confronting mathematics teachers and students in schools. For example, in a study, Yemi and Adeshina (2013) opined that teachers and students faced several challenges including lack of instructional materials, lack of motivation and overcrowding in class. 
Since poor academic performance of students in mathematics have been attributed to factors affecting both teachers and students globally; it is imperative that a study should be carried out to assess these factors affecting the teaching and learning of mathematics in Ghanaian SHS.

It is in the light of this, that this study was carried out to assess factors affecting teaching and learning of mathematics in some selected SHS in the Kumasi Metropolis of the Ashanti Region of Ghana.

\section{Purpose of the Study}

The purpose of the study was to assess factors affecting teaching and learning of mathematics in some selected SHS in the Kumasi Metropolis of the Ashanti Region. Specifically, this study intends:

1) To examine the factors affecting students in learning mathematics in the selected SHS in the Metropolis.

2) To assess the factors affecting mathematics teachers in the teaching of mathematics in the selected SHS in the Metropolis.

3) To find out strategies that could be used to improve SHS students' performance in mathematics.

\section{Research Questions}

The study was guided by the following three (3) research questions;

1) What are the factors affecting students in the learning of mathematics in the selected SHS in the Metropolis?

2) What are the factors affecting mathematics teachers in the teaching of mathematics in the selected SHS in the Metropolis?

3) What are the strategies that could be used to improve SHS students' performance in mathematics?

\section{Review of Related Literature}

This chapter discusses the review of related literature that supports the study. The sub-themes to be discussed in this aspect of the study are:

1) Factors Affecting Students in Learning Mathematics.

2) Factors Affecting Mathematics Teachers in the Teaching of Mathematics.

3) Strategies Used to Improve Students' Performance in Mathematics.

\section{Factors Affecting Students in Learning Mathematics}

Studies by (Lamb \& Fullarton, 2001; Nworgu, 2003; Al Shammeri, 2013; Udeh et al., 2017) have shown that there are several factors affecting SHS students in the learning mathematics in schools.

Studies by (Ezike \& Obodo, 1991; Obodo, 2004) stated that lack of hands-on activities, lack/inadequate activities in laboratory, lack of classroom furniture, poor teaching methods and lack of instructional resources are some of the factors that hinder effective learning of mathematics by students.

Lamb and Fullarton (2001) also pointed out that unconducive mathematics learning environment, students' lack of interest in mathematics, and students' poor understanding of mathematical concepts are factors confronting students learning of mathematics in schools.

In another study, Nworgu (2003) opined that lack of competent mathematics teachers; shortage of suitable qualified teachers and lack of good learning materials are three (3) major factors affecting students learning of mathematics in schools. The study concluded that most teachers do not possess the needed pedagogical knowledge in lesson delivery as well as the necessary competence in developing valid assessment instrument for evaluation of the behavioural out come in their domains.

Studies by (Obodo, 2004; Al Shammeri, 2013) posited that content difficulty, poor teaching methods, lack of learning resources, inadequate time allocated to the learning of mathematics and large class sizes are some of the major factors that affect students learning of mathematics in schools.

In a recent study, Udeh et al. (2017) posited that insufficient teachers, lack of textbook, lack of instructional materials and lack of mathematics laboratory are the four (4) major factors affecting the learning of mathematics by students in schools. 
It is obvious that literature is full of empirical evidence to suggest that SHS mathematics students globally are confronted with several factors that affect their learning of mathematics in schools.

\section{Factors Affecting Mathematics Teachers in the Teaching of Mathematics}

Studies by (Bajah, 2002; Delaney, 2012; Al Shammeri, 2013; Udeh et al., 2017) have indicated that there are several factors affecting teachers in the effective teaching of mathematics in schools.

In a study, Bajah (2002) indicated that lack of:- physical facilities, classroom furniture, teacher's demonstration table, equipment and apparatus, human resources and qualified teachers were some of the factors that hinder effective teaching of science and mathematics in schools.

A study by Delaney (2012) also found out that lack of mathematical pedagogical content knowledge by teachers as a result of inadequate professional training continues to be one of the major challenges affecting or hindering effective teaching of mathematics in schools.

In another study, Al Ghamdi and Al Saloudi (2012) revealed that inadequate instructional time, limited physical space, scarcity of teaching resources and inadequate training are crucial factors affecting mathematics teachers in the effective teaching of mathematics in schools.

A study on the barriers to effective teaching of mathematics, Al Shammeri (2013) found out that content difficulty, heavy workloads, lack of teaching resources, inadequate professional development, inadequate time allocated to the teaching of mathematics as well as large class sizes are some of the major factors affecting mathematics teachers in the teaching of mathematics.

In a study, Udeh et al. (2017) opined that lack of incentive for mathematics teachers, lack of instructional materials, and non-existence of mathematics laboratories for practical mathematics lessons are some of the major factors that hinders teachers in effective teaching of mathematics in schools.

It is obvious that literature is full of empirical evidence to suggest that there are number of factors affecting teachers in the effective teaching mathematics in senior high schools.

\section{Strategies Used to Improve Students' Performance in Mathematics}

Studies by (Ezike \& Obodo, 1991; Lynda, 2014; Schuck, 2016; Udeh et al., 2017) have indicated that there are several strategies that could be used by mathematics teachers to improve students' academic performance in mathematics in senior high schools.

Ezike and Obodo (1991) stated that the use of hands-on activities, given adequate laboratory activities, effective teaching methods and adequate instructional resources are some of the strategies that could be used to improve students' performance in mathematics in schools.

According to Lynda (2014), eclectic approach can be used by teachers to improve students' performance in science and mathematics. The study concluded that eclectic approach of teaching takes care of the diverse learners with different background settings; thus, making the teaching and learning of mathematics more interesting.

Schuck (2016) also stated integration of technology into the teaching and learning of mathematics as another strategy. The study concluded that integrating technology into the teaching and learning of mathematics enhances learning as learners gain access to current mathematical information, hand-on activities and mathematical video games at the click of a button.

Udeh et al. (2017) opined that provision of:- sufficient teachers, incentive for mathematics teachers, adequate textbook, and mathematics laboratory as well as supply of instructional materials are effective strategies that could be used to improve students' performance in mathematics in schools.

\section{Methodology}

\section{Research Design}

The research design used for this study was descriptive survey. The rationale for using this design was that the study sought to assess the views of elective mathematics SHS students and their mathematics teachers on the factors affecting teaching and learning of mathematics in some selected SHS.

According to Anane and Anyanful (2016), this research design allows the use of multiple data collection tools in seeking to address the research questions posed by the study in an in-depth manner. Again, this design gathers quantifiable information that can be used for statistical inference on the target audience through data analysis. 
However, descriptive survey has a weakness of being that the data gathered could produce untrustworthy results.

\section{Sample and Sampling Procedure}

The target population was all the SHS elective mathematics students and their teachers in the Ashanti Region of Ghana. However, the accessible population was all SHS elective mathematics students and their mathematics teachers in the Kumasi Metropolis. In all, a total of 90 respondents; made up of 10 SHS mathematics teachers and 80 SHS elective mathematics students drawn from five (5) SHS in the Metropolis were used for the study.

A purposive sampling technique of the non-probability sampling procedure was used to select the respondents for the study. These respondents were selected because of their in-depth knowledge on the factors confronting the teaching and learning of mathematics Ghanaian senior high school.

\section{Research Instruments}

Questionnaire and interview were the two (2) instruments used to collect data from the respondents. Two (2) questionnaires namely Mathematics Students' Questionnaire (MSQ) and Mathematics Teachers' Questionnaire (MTQ) were developed and used for the study. The MSQ was used to collect data from the 80 selected students whereas MTQ was used to collect data from the 10 teachers.

The MSQ had 14 question items structured into two (2) sections (A \& B). Section A had two (2) questions on the socio-demographic characteristics of the students whiles Section B comprised of 12 question items (i.e. 3 - 14) on the factors affecting SHS students in the learning of mathematics.

Also, the MTQ had 13 question items structured into two (2) sections (A \& B). Section A had one (1) question on the socio-demographic characteristics of teachers whiles Section B comprised of 12 question items (i.e. 2 - 13) based on the factors affecting mathematics teachers in the teaching of mathematics in the schools.

The interview was done using Respondents' Interview Guide (RIG). The RIG had only one (1) question item formulated based on the research question (3); that is strategies that could be used to improve students' academic performance in mathematics.

\section{Validity and Reliability of the Instruments}

The face and content validity of the instruments were established by having the instruments validated by two (2) Mathematics Education experts from the University of Education, Winneba. The reliability of these instruments was established by pilot-testing the instruments using 40 SHS elective mathematics students and 5 SHS teachers drawn from five (5) SHS in the Central Region of Ghana. The reliability analysis showed that the designed instruments were reliable and could be used for the study.

\section{Data Collection Procedure}

Permission was sought from the authorities, teachers and the students of the selected schools to carry out the study. Upon series of engagements and meetings, a date and time were agreed on to carry out the study in each of the selected school. In all, 15 days were used to collect data from respondents.

On the agreed date in each selected school, the MTQ was administered to the teachers whereas MSQ was also given to the students to answer in our presence for 50 minutes. After the stipulated time, all the questionnaires were collected and this process ensured $100 \%$ retrieval rate.

After, the administration of the questionnaire, a face-to-face interview session was conducted for only 40 students ( 8 students from each selected school) and all the 10 mathematics teachers using the question item in the RIG. The interview session lasted between 5-10 minutes for each student and between 10-20 for each teacher.

\section{Data Analysis Method}

The study used both quantitative and qualitative methods of data analysis. The question items in the questionnaires (MSQ \& MTQ) were analysed quantitatively using descriptive statistics mainly frequency and percentage. On the other hand, data from the RIG were also analysed qualitatively. 
Data obtained from the instruments were edited to ensure consistency. Statistical Package for Social Science (SPSS) version 20.0 for windows was used for data analysis; and Microsoft Excel Program was used to present the data into Tables.

\section{Results and Discussion \\ Analysis of the Results}

Data were collected by means of questionnaires (MSQ \& MTQ) and interview guide (RIG). Data from the questionnaires (MSQ \& MTQ) were analysed quantitatively using descriptive statistics namely frequency and percentage. The analysis of the results from the questionnaires were done and used to answer the research questions (1) and (2) that guided the study. Again, data obtained from the RIG were analysed qualitatively and used it to answer research question (3) that guided this study.

The analyses of the results from the questionnaires were done under four (4) thematic sections and are presented as follows;

1) Socio-demographic characteristics of students.

2) Socio-demographic characteristics of teachers.

3) Factors affecting SHS students in the learning of mathematics.

4) Factors affecting SHS mathematics teachers in the teaching of mathematics.

With the exception of the first two (2) analyses $(1 \& 2)$ on the socio-demographic characteristics of students and teachers; the other two (2) analyses ( $3 \& 4$ ) were done and used to answer the research questions (1) and (2) that guided the study.

\section{Analysis of Socio-Demographic Characteristics of Students}

The 80 SHS students' socio-demographic characteristics with regards to form/class and age were sought; and the findings with respect to form/class of the students are presented in Table 2 below:

Table 2: Form/Class of the Students

\begin{tabular}{|c|c|c|}
\hline Form/class & Frequency & Percentage (\%) \\
\hline SHS 1 & 21 & 26.2 \\
\hline SHS 2 & 27 & 33.8 \\
\hline SHS 3 & 32 & 40.0 \\
\hline Total & $\mathbf{8 0}$ & $\mathbf{1 0 0}$ \\
\hline
\end{tabular}

Source: (Mathematics Students' Questionnaire (MSQ), 2020)

Data in Table 2 shows that 21 students representing 26.2\% were in SHS 1; 27 students representing 33.8\% were in SHS 2 whereas 32 students representing 40.0\% were in SHS 3. Based on this statistics, it can be concluded that majority of the views expressed in this study were from SHS 3 students. This implies that SHS 3 students might be aware of factors affecting learning of mathematics in schools than SHS 1 and SHS 2 students; since they had studied mathematics in the school for the period of 2 years or more. Again, the ages of the students were also sought and are presented in Table 3 below:

Table 3: Age of the Students

\begin{tabular}{|c|c|c|}
\hline Age- range & Frequency & Percentage \\
\hline $12-14$ & 23 & 28.7 \\
\hline $15-17$ & 26 & 32.5 \\
\hline $18-20$ & 28 & 35.0 \\
\hline $21 \&$ above & 3 & 3.8 \\
\hline Total & $\mathbf{8 0}$ & $\mathbf{1 0 0}$ \\
\hline
\end{tabular}

Source: (Mathematics Students' Questionnaire (MSQ), 2020)

Data in Table 3 above shows that 28 students representing 35.0\% were between the ages of 18-20;26 students representing $32.5 \%$ were between the ages of $15-17 ; 23$ students representing $28.7 \%$ were between the ages 12-14; whiles only 3 students representing $3.8 \%$ were $21 \&$ above. 
Based on data in Table 3, it can be concluded that majority of the views expressed in this study were from SHS students between the ages of 18-20, and were considered to be matured, according to the 1992 Constitution of Ghana. Again, the sex of the 10 SHS mathematics teachers who took part in the study was also sought and are presented in Table 4 below:

Table 4: Sex of the 10 Selected Mathematics Teachers

\begin{tabular}{|c|c|c|}
\hline Sex & Frequency & Percentage \\
\hline Male & 7 & 70.0 \\
\hline Female & 3 & 30.0 \\
\hline Total & $\mathbf{1 0}$ & $\mathbf{1 0 0}$ \\
\hline
\end{tabular}

Source: (Mathematics Teachers' Questionnaire (MTQ), 2020)

Data in Table 4 shows that 7 mathematics teachers representing $70.0 \%$ were males whiles only 3 mathematics teachers representing $30.0 \%$ were females. This indicates that majority of the teachers' views expressed in this study were from male mathematics teachers and that males tend to teach mathematics than female teachers.

\section{Presentation of Results by Research Questions \\ Research Question 1: What are the factors affecting students in the learning of mathematics in the selected SHS in the Metropolis?}

In answering research question 1, all the 80 SHS elective mathematics students' answers to question items (3 - 13) in mathematics students' questionnaire (MSQ) were analysed quantitatively using descriptive statistics and are presented in Table 5 below:

Table 5: Students' Responses on Factors Affecting Learning of Mathematics

\begin{tabular}{|c|l|c|c|}
\hline No. & Factors affecting students learning of mathematics. & Frequency & Percentage \\
\hline 3). & Lack of mathematics laboratories/practical rooms. & 80 & 100 \\
\hline 4$).$ & Lack of good learning materials. & 79 & 98.8 \\
\hline 5). & Lack/inadequate mathematics practical activities. & 80 & 100 \\
\hline 6). & Students' fear of mathematics subject. & 77 & 96.3 \\
\hline 7$).$ & Use of lecture method in teaching mathematics. & 80 & 100 \\
\hline 8). & Lack of furniture and space in classrooms. & 78 & 97.5 \\
\hline 9). & Lack of competent mathematics teachers. & 54 & 67.5 \\
\hline 10). & Lack of parental support. & 76 & 95.0 \\
\hline 11). & Unconducive mathematics learning environment. & 46 & 57.5 \\
\hline 12). & Unavailability of relevant mathematics textbooks. & 71 & 88.8 \\
\hline 13). & Limited mathematics periods on time table. & 55 & 68.8 \\
\hline & Total & $\mathbf{8 0}$ & $\mathbf{1 0 0}$ \\
\hline
\end{tabular}

Source: (Mathematics Students’ Questionnaire (MSQ), 2020)

Responses in Table 5 show that there are several factors that impede or affect SHS students learning of mathematics in schools. From Table 5, it was revealed that all the 80 SHS students representing 100\% indicated that lack of mathematics laboratories/practical rooms; lack/inadequate mathematics practical activities and the use of lecture method in teaching mathematics were the major factors affecting students learning of mathematics in schools.

Again, 79 students representing $98.8 \%$ mentioned lack of good learning materials; 78 students representing 97.5\% stated lack of furniture and space in classrooms; 77 students representing $96.3 \%$ indicated students' fear of mathematics subject; 76 students representing $95.0 \%$ lack of parental support whereas 71 students representing $88.8 \%$ also opined unavailability of relevant mathematics textbooks are some of the factors affecting SHS students learning of mathematics in the school.

Other factors mentioned by the students in response to question item 14 in the students' questionnaire include difficult topics in mathematics; abusive language used by teachers during teaching; threating and 
unfriendly mathematics learning environment; mathematics teacher's poor attitude towards teaching; teacher's regular absenteeism, laziness on the part of some mathematics teachers and lack of computers and other resources for student's private studies at home.

The data in Table 5 above showed that SHS elective mathematics students who took part in this study were faced with numerous challenges with regards to their learning of mathematics in schools.

\section{Research Question 2: What are the factors affecting mathematics teachers in the teaching of mathematics in the selected SHS in the Metropolis?}

In answering research question 2, all the 10 SHS mathematics teachers' responses to question items (2 - 13) in the mathematics teachers' questionnaire (MTQ) were analysed quantitatively using descriptive statistics (i.e. frequency \& percentages) and are presented in Table 6 below:

Table 6: Teachers' Responses on Factors Affecting Mathematics Teaching

\begin{tabular}{|c|l|c|c|}
\hline No. & Factors affecting teachers in the teaching of mathematics & Frequency & Percentage \\
\hline 2). & Lack of teaching and learning materials (TLMs). & 10 & 100 \\
\hline 3$).$ & Insufficient mathematics periods on time table. & 5 & 50 \\
\hline 4$).$ & Presence of students' misconceptions in mathematics. & 8 & 80 \\
\hline 5$).$ & Overcrowded mathematics classrooms. & 9 & 90 \\
\hline 6). & Lack of in-service training for mathematics teachers. & 7 & 70 \\
\hline 7$).$ & Heavy workload on mathematics teachers. & 10 & 100 \\
\hline 8). & $\begin{array}{l}\text { Unfriendly assessment method using exams scores for } \\
\text { achievement criterion. }\end{array}$ & 9 & 90 \\
\hline 9). & Student's poor attitude towards mathematics teachers & 6 & 60 \\
\hline 10). & Lack of teacher's demonstration table. & 5 & 50 \\
\hline 11). & Lack of mathematics laboratories/practical rooms. & 10 & 100 \\
\hline 12). & Insecure mathematics teaching environments. & $\mathbf{1 0}$ & 40 \\
\hline & \multicolumn{1}{|c|}{ Total } & & $\mathbf{1 0 0}$ \\
\hline
\end{tabular}

Source: (Mathematics Teachers' Questionnaire (MTQ), 2020).

Data in Table 6 reveals that SHS mathematics teachers who took part in the study are confronted with numerous factors that affect or impede effective teaching of mathematics. From Table 6 above, it was revealed that all the 10 SHS mathematics teachers representing $100 \%$ indicated that lack of teaching and learning materials (TLMs); heavy workload on mathematics teachers and lack of mathematics laboratories/practical rooms were the major factors affecting mathematics teachers in the teaching of mathematics in the senior high school.

Again, 9 mathematics teachers representing 90\% indicated that overcrowded mathematics classrooms; and unfriendly assessment method using exams scores for achievement criterion were some of the factors affecting the teaching of mathematics.

Also, 8 mathematics teachers representing $80 \%$ stated presence of students' misconceptions in mathematics; 7 teachers representing $70 \%$ mentioned lack of in-service training for mathematics teachers; 6 teachers representing $60 \%$ indicated student's poor attitude towards mathematics teachers; whereas 5 teachers representing 50\% also mentioned lack of teacher's demonstration table as some of the factors affecting SHS mathematics teachers in effective teaching of mathematics.

Other factors mentioned by teachers in response to question item 13 in the teachers' questionnaire include lack of parental support in provision of basic needs for students; unavailability of relevant textbooks; influence of superstitions and culture towards mathematics teaching; lack of professional development for teachers by government; and student's poor attitude towards mathematics.

The data in Table 6 above showed that there were several factors that affect or hinder SHS mathematics teachers in ensuring effective teaching of mathematics in the selected schools.

Research Question 3: What are the strategies that could be used to improve SHS students' performance in mathematics? 
In answering research question 3, the respondents' (SHS students \& teachers) responses to question one (1) on the strategies that could be used to improve students' performance in mathematics in the respondents' interview guide (RIG) were analysed qualitatively and are presented in Table 7 below:

Table 7: Strategies Used To Improve Students' Performance In Mathematics

\begin{tabular}{|c|l|}
\hline No. & Strategies to improve students' performance in mathematics \\
\hline 1). & Using eclectic methods to cater for the students' diverse needs in class. \\
\hline 2$).$ & Embarking on field trips to mathematics related industries. \\
\hline 3$).$ & Attachment of mathematics students to role models. \\
\hline 4$).$ & Provision of mathematics laboratories/practical rooms. \\
\hline 5). & Provision of appropriate gender-based mathematics textbooks. \\
\hline 6$).$ & Using resource person in mathematics teaching. \\
\hline 7). & Using motivational strategies in mathematics teaching. \\
\hline 8$).$ & Provision and use of appropriate TLMs in mathematics teaching. \\
\hline 9$).$ & Use peer and cooperative teaching strategies. \\
\hline 10$).$ & Engaging students in hands-on and minds-on oriented lessons. \\
\hline 11$).$ & Eliciting students' misconceptions and adopt strategies to solve them \\
\hline 12$).$ & Provision of relevant mathematics textbooks for students. \\
\hline 13$).$ & Giving students regular assignments, exercises and home work to do. \\
\hline
\end{tabular}

Source: (Respondents’ Interview Guide (RIG), 2020)

Data in Table 7 above shows that there are several strategies that could be used to improve students' academic performance in mathematics in senior high schools. Some of the strategies mentioned by the respondents during interview sessions include using eclectic methods to cater for the students' diverse needs in class; provision of mathematics laboratories/practical rooms; provision and use of appropriate TLMs in mathematics teaching; engaging students in hands-on and minds-on oriented lessons; eliciting students' misconceptions and adopt strategies to solve them; using motivational strategies in mathematics teaching; provision of relevant mathematics textbooks for students; and giving students regular assignments, exercises and home work to do.

The responses in Table 7 above showed that there were several strategies that could be used to improve students' academic performance in mathematics in schools.

\section{Discussion of the Results}

The results of this study showed that there were several factors that affect SHS students in the learning of mathematics. The major factors identified as indicated by all the 80 students representing $100 \%$ were lack of mathematics laboratories/practical rooms; lack/inadequate mathematics practical activities and the use of lecture method in teaching mathematics. Moreover, lack of good learning materials; students' fear of mathematics subject; lack of parental support; unavailability of relevant mathematics textbooks; difficulty topics in mathematics; and abusive language used by teachers during teaching were other factors affecting SHS students learning of mathematics. This implies that there were several factors that affect SHS students in the learning of mathematics in the selected SHS. This result agrees with the findings of (Lamb \& Fullarton, 2001; Nworgu, 2003; Al Shammeri, 2013; Udeh et al., 2017) that there are several factors affecting SHS students in the learning of mathematics in schools.

It was also found out that the most common factors affecting mathematics teachers in the teaching of mathematics as indicated by all the 10 SHS mathematics teachers representing $100 \%$ were lack of TLMs; heavy workload on mathematics teachers and lack of mathematics laboratories/practical rooms. Other factors identified include overcrowded mathematics classrooms; presence of students' misconceptions; lack of in-service training for mathematics teachers; unavailability of appropriate and relevant textbooks and influence of superstitions and culture towards mathematics teaching. This result in agreement with the findings of (Bajah, 2002; Delaney, 2012; Al Shammeri, 2013; Udeh et al., 2017) that there are several factors affecting teachers in the effective teaching of mathematics in schools. 
Finally, the study revealed that there were several strategies that could be used to improve students' academic performance in mathematics. Some of the strategies identified by the respondents include provision and use of appropriate TLMs in mathematics teaching; using eclectic methods to cater for the students' diverse needs in class; provision of mathematics laboratories/practical rooms; engaging students in hands-on and minds-on oriented lessons; eliciting students' misconceptions and adopt strategies to solve them; and using motivational strategies in mathematics teaching. This result is consonance with findings of (Ezike \& Obodo, 1991; Lynda, 2014; Schuck, 2016; Udeh et al., 2017) that there are several strategies that could be used by mathematics teachers to improve students' academic performance in mathematics in senior high schools.

\section{Conclusions}

Based on the key findings of the study, the following conclusions were drawn:

1) It can be concluded that lack of mathematics laboratories/practical rooms; lack/inadequate mathematics practical activities and the use of lecture method in teaching mathematics were the three (3) major factors affecting SHS students learning of mathematics in schools.

2) It can also be concluded that lack of good learning materials; students' fear of mathematics; lack of parental support; difficult topics in mathematics; and abusive language used by teachers during teaching were other factors affecting SHS students with regards to learning of mathematics.

3) It can be concluded that lack of TLMs; heavy workload on mathematics teachers and lack of mathematics laboratories/practical rooms were the three (3) major identified factors affecting mathematics teachers in the teaching of mathematics in schools.

4) It can be concluded that overcrowded mathematics classrooms; presence of students' misconceptions; lack of in-service training for teachers; and influence of superstitions and culture towards mathematics were the other factors affecting teachers in the teaching of mathematics.

5) Finally, it can be concluded that provision and use of appropriate TLMs in teaching mathematics; provision of mathematics laboratories/practical rooms; using eclectic methods to cater for students' diverse needs in class; engaging students in hands-on and minds-on oriented lessons; and eliciting students' misconceptions and adopt strategies to solve them were some of the strategies that could be used to improve students' academic performance in mathematics.

\section{Recommendations}

Based on the major findings and conclusions drawn, it is recommended that: -

1) Government of Ghana and other stakeholders in SHS education should build mathematics laboratories/practical rooms in all SHS in the country and also equip them with requisite TLMs so that students can learn mathematics in more practical-oriented manner instead theoretical approach being used in senior high schools.

2) Mathematics teachers should use varied teaching approach in teaching mathematics so as to cater for diversity or individual needs in the mathematics classroom.

\section{Acknowledgements}

The authors are very grateful to the authors of the books and materials we consulted to ensure successful completion of this article. We also thank all people; most especially the respondents who willingly participated in this study. Finally, we are thankful to reviewers of this article for their quick response, comments and suggestions to ensure successful completion of this article. We say thank you.

\section{References}

[1] Abubakar, B.M (1980). Opening address at the national conference on mathematics and mathematics education. Lagos, Nigeria.

[2] Al Ghamdi, A. H., \& Al Saloudi, M. S. (2012). Saudi elementary school mathematics teachers' beliefs: teaching mathematics in the new millennium. International Journal of Science \& Mathematics Education, 11(2), 501-525.

[3] Al Shammeri, M. M. (2013). Curriculum implementation and reform: teachers' views about Kuwait's new mathematics curriculum. US-China Education Review, 3(3), 1- 6. 
[4] Anane, E., \& Anyanful, V. K. (2016). Guide for writing and presenting project work. University of Cape Coast, Cape Coast, Ghana.

[5] Appiahene, P., Opoku, M., Akweittey, E., Adoba, E., \& Kwarteng R. (2014). Assessing the challenges of learning and teaching of mathematics in second cycle institutions in Ghana. International Journal of Innovation and Applied Studies, 6 (3), 362-368

[6] Attah, B.G (2009). Quality, skills, and efficacy of primary and secondary schools mathematics teachers in Nigeria. Journal of educational studies 14(1), 124-127

[7] Bajah, S. T., (2002). Mathematics and sciencing with children; a solid foundation for our future mathematician and scientists; innovative. Faculty of Education; lecture series. Unilag series.

[8] Buabeng, I., Owusu, A. K., \& Ntow, D. F. (2014). TIMSS 2011 mathematics and science assessment results: a review of Ghana's performance. Journal of Curriculum and Teaching, 3(2), 1-14.

[9] Delaney, S. (2012). Problems in teaching primary school mathematics. Unpublished $\mathrm{PhD}$ Dissertation, Uni. of Illinois.

[10] Ezike, R.O., \& Obodo, G. C. (1991). The teaching of mathematics in schools and colleges. EhaAmufu, Division of General studies collages of education, Enugu state.

[11] Fasasi, K. M. (2009). Institutional impediments associated with students' failure in mathematics in secondary schools in Adamawa state. Journal of education studies 14(1), 92-98.

[12] Heck, R. H. (2009). Teacher effectiveness and student achievement: investigating a multilevel crossclassified model. J. of Education Administration, 7 (22), 227-249.

[13] Kimani, G. N., Kara, A. M., \& Njagi, W. L. (2013). Teacher factors influencing mathematics students' academic achievement in secondary schools in Nyandarua. County, Kenya. International Journal of Education and Research, 1(3), 1-14.

[14] Lamb, S., \& Fullarton, S. (2001). Classroom and school factors affecting mathematics achievement: comparative study of the US and Australia using TIMSS. Australian Council for Educational Research (ACER) ACEReSearch. Pp 4 - 20. Retrieved August 20, 2020 from, https://research.acer.edu.au/timss_monographs/10.

[15] Lynda, W. (2014). Strategies for educators to support females in STEM. Uni., of Nevada. New York

[16] Mitchell Group, (2009). Education in Ghana: progress and problems.

[17] Nworgu, B. G. (2003). Educational measurement and evaluation: theory and practice. Nsukka: university publishers.

[18] Obodo, G. C. (2004). Principles and practice of mathematics education in Nigeria. Enugu: Nigeria Floxtone press.

[19] Odhiambo, G. (2005). Elusive search for quality mathematics education. International Journal of Education Management, 22(5), 417- 431.

[20] Schuck, A. F. (2016). Quality, skills, and efficacy of primary and secondary schools mathematics teachers in Nigeria. Journal of educational studies, 14(1), 124-127

[21] Stephen, T.K (2009). The role of mathematics as a foundation for education of children in science and technology in the universal basic education. Journal of Educational Studies 14(1), 146 - 151.

[22] Udeh, I. J., Edeoga, B. O., \& Okpube, N. M. (2017). Problems and factors affecting the teaching of mathematics in secondary schools. International Research Journal of Mathematics, Engineering and IT, 4(11), 13 - 23.

[23] WAEC Mathematics Chief Examiners Reports (2014-2018). Mathematics chief examiner's annual reports on WAEC/WASSCE mathematics results. MOE; Accra, Ghana.

[24] Yemi, T. M., \& Adeshina, A. N. G. (2013). Factors influencing effective learning of mathematics at senior secondary schools within Gombe Metropolis, Gombe State Nigeria. Journal of Education and Practice, 4(25), 61- 66. 